\title{
Aspectos da inovação para televisão digital
}

Alan César Belo Angeluci

Doutor em Ciências pela Escola Politécnica da Universidade de São Paulo. Pós-doutorando pelo Departamento de Radio-Television-Film da Universidade do Texas, em Austin, EUA.

Pesquisador do Centro Interdisciplinar em Tecnologias Interativas (CITI-USP).

E-mail: aangeluci@usp.br

Marília da Silva Franco

Professora Doutora do Departamento de Cinema, Rádio e TV da Escola de Comunicações e Artes da Universidade de São Paulo.

E-mail: marilia.franco@gmail.com

Resumo: Em estudos interdisciplinares sobre televisão digital, verifica-se a ocorrência de fundamentos conflitantes no que tange à natureza transformadora dessa mídia, que ora é definida como revolução, ora como inovação. À luz dos conceitos de gênero/movimento da linguagem audiovisual e a partir de uma abordagem histórica, identificaram-se requisitos que aproximam a televisão digital mais ao fundamento da inovação. Acionamentos transgressores, no entanto, podem apontar horizontes de superação do status quo, a partir de espaços de experimentação e invenção social que permitem à tecnologia exercitar seu potencial reflexivo.

Palavras-chave: televisão interativa; televisão digital; revolução; inovação.
Abstract: In interdisciplinary studies on digital television, we see an occurrence of conflicting arguments on the transforming nature of these media, which is sometimes defined as revolution, sometimes as innovation. From the concepts of genre/movement of audiovisual language and considering a historical approach, we identified some requirements that approximate the digital television to the innovation argument. Transgressor mechanisms, however, can indicate horizons to overcome the status quo, from spaces of experimentation and social intervention which allow the technology to practice its reflexive potential.

Keywords: interactive television; digital television; revolution; innovation.

\section{INTRODUÇÃO}

A buzzword "televisão interativa", que de tempos em tempos volta à cena no campo da comunicação, assumiu uma nova roupagem com as discussões sobre televisão digital no Brasil. A mais recente enciclopédia brasileira que trata dos termos que permeiam os estudos no campo da comunicação define televisão digital como "uma plataforma capaz de agregar diversos serviços, apresentando-se, assim, como uma importante ferramenta para o campo do audiovisual"1. Vista, portanto, sob o símbolo da ferramenta, sua função se estabelece a partir do uso potencial.

A especulação sobre as potencialidades da televisão digital e seus impactos criou um sem-número de ruídos conceituais que podem comprometer não só a compreensão de pesquisadores e profissionais da área, mas também de cidadãos

Recebido: $28 / 03 / 2013$

Aprovado: 06/10/2013

1. ENCICLOPÉDIA INTERCOM DE COMUNICAÇÃO. José Marques de Melo (org.). São Paulo: Sociedade Brasileira de Estudos Interdisciplinares da Comunicação, 2010, v. 1, p. 1163. 
comuns instigados pelo tema. Neste artigo, a televisão é observada a partir da expressão da linguagem audiovisual, como um fenômeno que deve ser analisado considerando sua trajetória histórica e marcos que delinearam seu modus operandi. Esta retrospectiva colabora para situar a televisão a partir de dois fundamentos que podem por vezes caminhar em direções opostas: o da revolução e o da inovação. Situada sob a ótica da inovação, no entanto, uma tecnologia aplicada a essa mídia pode ter o potencial de atuar de forma a promover modificações estruturais em ambientes com modelos de negócio consolidados e fechados.

\section{TRANSFORMAÇÃO, INOVAÇÃO E REVOLUÇÃO}

Algumas expressões são comumente utilizadas para exprimir um sentido de transformação de um estado de coisas para outro diferente do inicial. O processo de transformação pode ser definido à luz de variadas correntes teóricas. Quando o sociólogo Bauman² expressa esse processo a partir da metáfora da liquidez, busca sintetizar a ideia de uma sociedade pós-moderna cujos valores e ideologias cada vez mais se diluem e se ressignificam. Da mesma forma, a pedagogia freireana considera a transformação social o objetivo fundamental de uma tomada de consciência coletiva e da problematização no processo educativo $^{3}$. A transformação também está presente nas obras de Karl Marx, Adam Smith e tantos outros, que serviram de bases conceituais para mudanças políticas, econômicas e sociais experimentadas pela sociedade nos últimos anos.

Porém, uma retomada aos tempos mais longínquos nos situa entre os filósofos pré-socráticos como Heráclito, que também se dedicaram a essa matéria. Considerado um dos precursores do pensamento racionalista de Descartes e Bacon, Heráclito dedicou-se ao conceito de transformação a partir da observação do fogo, cujas chamas nunca são permanentemente as mesmas. A dialética de Hegel tinha como premissa a compreensão da realidade como fundamentalmente contraditória e em constante transformação. Já a antiga filosofia oriental também buscou referências a partir do conceito do yin-yang, em que o princípio da mudança constante é o principal fundamento.

A ideia generalista de transformação pode ser a base para que se possa compreender a essência do significado dos termos "inovação" e "revolução". Ambas têm relação com a ideia de transformação, no entanto possuem características específicas que as diferenciam grandemente. O conceito de revolução tem raízes na filosofia grega de pensadores como Aristóteles e é constantemente empregado em questões sociopolíticas, principalmente a partir de reflexões na área de Ciências Sociais. Dessa forma, os eventos de grande transformação sociopolítica que se su-

2. BAUMAN, Z. Modernidade líquida. Rio de Janeiro: Jorge Zahar, 2001, p. 107.

3. FREIRE, P. Pedagogia do oprimido. 18. ed. Rio de Janeiro: Paz \& Terra, 1988, p. 44. cederam na história da humanidade são frequentemente descritos como revolução.

O conceito de inovação também tem suas raízes nas Ciências Sociais, porém se configura como um termo extremamente polissêmico e, até a década de 1960, existiam poucos estudos empíricos que garantiam o avanço na compreensão do significado de inovação. Com sua origem atrelada às teorias econômicas postuladas por Joseph Schumpeter, atualmente o conceito se apoia em uma perspectiva mais sistêmica: 
O conceito de inovação não se restringe a processos de mudanças radicais na fronteira tecnológica, realizados quase que exclusivamente por grandes empresas através de seus esforços de pesquisa e desenvolvimento ( $\mathrm{P} \& \mathrm{D})$. São importantes as consequências do reconhecimento de que a inovação se estende para além das atividades formais de P\&D e inclui novas formas de produzir bens e serviços, que lhe são novos, independentemente do fato de serem novos, ou não, para os seus competidores ${ }^{4}$.

Notavelmente concebido para expressar as características de uma sociedade pós-revolução industrial e capitalista, o conceito de inovação se situa em um contexto em que a sociedade está condicionada à pressão dos avanços tecnológicos, às mudanças no consumo, nas necessidades e nos modelos de negócio, bem como à intensificação da concorrência ${ }^{5}$. No entanto, outras correntes se dedicam a combater o sentido mercadológico ao qual o termo tem sido atrelado, dando ênfase ao potencial impacto social positivo das tecnologias e seu uso para a transformação de uma realidade de populações sujeitas à brecha digital ${ }^{6}$.

\section{INOVAÇÃO E REVOLUÇÃO NO AUDIOVISUAL}

A linguagem audiovisual é uma expressão estética (aesthesis, do grego: sensibilidade) e, portanto, sensível fisiologicamente ao ser humano. Atua diretamente no campo das emoções humanas seduzindo esteticamente o público, favorecendo a assimilação e acomodação do conhecimento ${ }^{7}$. Não à toa, quando da primeira exibição pública de um filme, em 1895, o público se assustou com a cena de um trem vindo em sua direção e saiu correndo assustado da sala de projeção. Comparada com as artes plásticas, dança ou música, o cinema é uma arte recente, de pouco mais de cem anos. Contudo, suas principais referências datam de 5000 a.C., quando chineses faziam a projeção de objetos sobre paredes e telas e contavam histórias.

Quando Georges Méliès descobriu, no começo do século XX, que conseguia provocar efeitos em suas imagens através da manipulação do equipamento de captação, inaugurou-se a ficção audiovisual. Da mesma forma, D.W. Griffith percebeu o potencial narrativo dos enquadramentos e ângulos e criou a montagem ${ }^{8}$. Méliès e Griffith, considerados nomes essenciais na consolidação do cinema e do audiovisual, produziram no início do século passado conteúdos que expressavam a "magia" tecnológica e o desejo humano de poder criar meios que inovam a linguagem da narrativa audiovisual, já que essa narrativa é a própria construção da cultura humana.

Nos Estados Unidos, o cinema foi rapidamente assimilado à cultura da industrialização que o país vivia no início do século XX e tornou-se o primeiro produto da indústria cultural. Como produto, adotou um padrão que respondesse à produção em massa e passou a organizar seus conteúdos a partir da lógica da máquina capitalista, categorizando suas produções em gêneros. Estabeleciam-se, dessa forma, filmes de padrões narrativos com estruturas predefinidas. Os estudos de Propp ${ }^{9}$ sobre as 31 funções narrativas serviram de referência para gêneros conhecidos e explorados até hoje. É a partir do cinema norte-americano que o hábito de ir ao cinema é consolidado em todo mundo, o que tornou a indústria cinematográfica a mais lucrativa por décadas, só perdendo recentemente para os games.
4. CASSIOLATO, J.E.; LASTRES, H. M. M. Sistemas de inovação e desenvolvimento: as implicações de política. São Paulo em Perspectiva, v. 19, n. 1 , pp. $34-45,2005$

5. GOFFIN, K.: RICK, M. Innovation Management: Strategy and Implementation using the Pentathlon Framework. 2 ed. Nova York: Palgrave Macmillan, 2010, p. 3.

6. BARBOSA FILHO, A. CASTRO, C. Comunicação digital: educação, tecnologia e novos comportamentos. 1. ed. São Paulo: Paulinas, 2008, p. 41.

7. PIAGET, J. Biologia e conhecimento. 2. ed Vozes: Petrópolis, 1996, p. 266.

8. MARTIN, M. A linguagem cinematográfica. São Paulo: Brasiliense, 2003 , p. 38

9. PROPP, V. Morfologia do conto maravilhoso. Trad. Jasna Paravich Sarhan. Rio de Janeiro: Forense Universitária, 1984, p. 19. 
A linguagem audiovisual também seguiu por caminhos diferentes dos comerciais. Nos anos 1920, várias linguagens estéticas se engajaram em movimentos que se posicionavam criticamente contra o humanismo. Surgiram, então, o dadaísmo, o cubismo, o surrealismo, entre outros. O cinema europeu buscou um modelo diferente que atendia não às necessidades capitalistas, mas a uma relação simbiótica entre expressão estética e sociedade. Essa forma de estruturar o cinema tinha como base fundamentos filosóficos, políticos e ideológicos que impactavam diretamente em sua estética.

Desta maneira, o cinema expressionista alemão buscava o exagero na apresentação, projeção e identificação do direito individual do homem. Uma estética eufórica e disfórica, do claro e escuro, baseada em primeiros planos, como pode ser observado em O gabinete do Doutor Caligari (Robert Wiene, 1920), primeiro filme expressionista. $\mathrm{O}$ cinema russo buscou também em sua estética uma maneira de representar os ideais socialistas por meio da ênfase aos grupos e heróis coletivos, com predomínio dos planos gerais (como em $O$ encouraçado Potemkin, de Serguei Eisenstein, 1925). Seguiu nessa mesma perspectiva a vanguarda francesa com sua narrativa mais reflexiva, e o neorrealismo italiano com filmes rodados na rua e não exclusivamente no estúdio.

Vemos, portanto, a partir da trajetória do cinema, como a linguagem audiovisual evoluiu em dois principais modelos distintos apresentados na Tabela 1: um norte-americano, baseado na indústria de massa, de inovação tecnológica e na conformação dos gêneros; outro europeu, com base em movimentos de engajamento revolucionário ou escolas estéticas de propostas filosóficas, políticas e ideológicas. Em síntese, são modelos que representam o fundamento da inovação e o da revolução na linguagem audiovisual, a partir das condições socioculturais que direcionam a escolha dos modelos de negócio e, portanto, determinados acionamento das tecnologias.

Tabela 1 - Diferenças entre os modelos de linguagem audiovisual

\begin{tabular}{|c|c|}
\hline INOVAÇÃo & REVOLUÇÃo \\
\hline Cinema norte-americano & Cinema europeu \\
\hline Padrão, conservador & Transgressor \\
\hline Ilusão de mudança, \\
manutenção da estrutura & Modificação da estrutura \\
\hline Categorização por gênero & Movimento ou escola \\
\hline Postura capitalista & Postura filosófica e política \\
\hline Ênfase na tecnologia & Ênfase na sociedade \\
\hline Espetáculo, alienação & Reflexão, libertação \\
\hline Consumo & Formação ideológica \\
\hline
\end{tabular}




\section{INOVAÇÃO E TELEVISÃO}

A televisão, como linguagem audiovisual que deriva do cinema e se desenvolve no final da primeira metade do século XX, surge imersa nessa cultura capitalista e muito rapidamente assimila os conceitos de inovação que vão conformar sua estrutura. Desde seus primeiros anos até a atualidade, a televisão teve seu desenvolvimento pautado na inovação tecnológica e seus impactos na linguagem alterando, de tempos em tempos, o modo de produção, distribuição e recepção.

Entre as mais notáveis estão a chegada do videotape, da transmissão via satélite, do sistema de cores e do controle remoto ${ }^{10}$. Essas inovações tecnológicas permitiram que os conteúdos pudessem ser gravados, transmitidos em maior escala com qualidade e selecionados pela audiência em casa. A Tabela 2 sintetiza as principais inovações no campo da radiodifusão ao longo dos anos.

Tabela 2 - Inovações no campo da radiodifusão televisiva

\begin{tabular}{|c|c|c|c|c|c|}
\hline Anos 1960 & Anos 1970 & Anos 1980 & Anos 1990 & Anos 2000 & Anos 2010 \\
\hline $\begin{array}{c}\text { videotape; } \\
\text { consolidação } \\
\text { das redes }\end{array}$ & TV a cores & $\begin{array}{c}\text { controle } \\
\text { remoto }\end{array}$ & $\begin{array}{c}\text { videocassete; } \\
\text { ilhas de } \\
\text { edição não } \\
\text { linear }\end{array}$ & $\begin{array}{c}\text { DVD; } \\
\text { blu-ray; } \\
\text { TV digital }\end{array}$ & $\begin{array}{c}\text { TV conectada; } \\
\text { múltiplos } \\
\text { dispositivos; } \\
\text { aplicações interativas }\end{array}$ \\
\hline
\end{tabular}

No caso brasileiro, a televisão importada nos moldes norte-americanos encontrou no país terreno fértil para se desenvolver como produto cultural. Com a chegada do rádio na década de 1920 e da televisão na década de 1950, os meios de comunicação eletrônicos tornaram-se as principais fontes de acesso à informação sobre o que ocorria no país e no mundo ${ }^{11}$, em tempos em que grande parte da população era analfabeta ou tinha baixo letramento. A televisão não exigia grandes capacidades de leitura, mas, sim, habilidades de ver, ouvir e compreender - uma prática de oralidade mais próxima às condições da época.

A televisão no Brasil também assimilou os conceitos de inovação, incutindo a estrutura capitalista de linha de produção na organização da emissora, desde sua visão macro de cabeça de rede e afiliada até a rotina de produção baseada em funções distintas. A produção do conteúdo também foi organizada em gêneros, distribuídos em uma grade de programação com horários definidos.

O telejornal, por exemplo, representou um importante momento na radiodifusão brasileira nos fins dos anos 1960. A consolidação da rede, uma iniciativa altamente tecnológica para a época, contribuiu para o surgimento do Jornal Nacional, da Rede Globo, criando uma inovação sem precedentes na radiodifusão brasileira e que teve impactos positivos importantes no share publicitário e na edição dos conteúdos:

Esse esforço de expansão rápida da rede é que explica o surgimento do Jornal Nacional, em $1^{\circ}$ de setembro de 1969, o primeiro programa em rede nacional da televisão brasileira. Nós precisávamos de um programa diário, que entrasse ao vivo em vários estados, para estimular outras emissoras a se afiliarem à Rede Globo. Com mais emissoras, podíamos oferecer aos nossos clientes a audiência de outras
10. MATTOS, S. A. S História da televisão brasileira. Uma visão econômica, social e política. 2. ed. Petrópolis: Vozes, 2002, p. 169. 11. MATTOS, S. A. S., idem, p. 35. 
12. CLARK, V.; PRIOLLI,

G. O campeão de audiência. São Paulo: Best

Seller, 1991, p. 213

13. CONSULTORIA J. LEIVA E FUNDAÇÃO GETÚLIO VARGAS. O que é cultura? Disponível em: <www.jleiva.com $\mathrm{br} / \mathrm{wp}$-content/themes/ jleiva/_conteudo/pdf/relatorio_habitos_culturais. pdf $>$. Acesso em: 08 mar. 2014

14. ALENCAR, M. S.; MADEIRO, F.; LOPES, W. T. A. History of Television in Brazil. Proc. of the IEEE Conference on History of Telecommunications 2010 (HISTELCON 2010), Madri, Espanha, nov. 2010, p. 2.

15. ANATEL. (2011). Cobertura da TV digital. Contagem da população. Disponível em: <www. anatel.gov.br/Portal/verificaDocumentos/documento.asp?numeroPubli cacao $=276895$ \&assuntoP ublicacao $=$ Popula\%E7\% E3०\%20alcan\%E7ada\&ca minhoRel=null\&filtro $=1 \&$ documentoPath $=276895$. pdf $>$. Acesso em: 08 mar. 2014. praças, cobrando mais caro por isso. E, obviamente, não havia nenhum programa de TV diário melhor para fazer essa integração nacional do que um telejornal ${ }^{12}$.

A influência da TV na sociedade brasileira se explica a partir de dados: 97\% dos lares brasileiros possuem ao menos um televisor; atualmente a população prefere se entreter e se informar por meio de conteúdos audiovisuais ${ }^{13}$. As inovações no setor atingem tamanho grau de sofisticação que foi possível transformar os sinais de transmissão de radiodifusão até então analógicos em digitais, abrindo um campo de possibilidades em todas as cadeias de produção em televisão e uma nova fase na história deste meio de comunicação.

Atualmente, o Brasil tem se afirmado na vanguarda da inovação das tecnologias de radiodifusão dentro da América Latina. Com o tripé da alta definição, interatividade e mobilidade, o governo brasileiro tem buscado a consolidação de um sistema sul-americano de televisão digital. Tal sistema é estratégico para o país do ponto de vista de detenção e exportação de serviços e mão de obra especializada. Adicionalmente, o desenvolvimento de uma política de inovação tecnológica a longo prazo interligada ao estímulo de uma indústria de conteúdos digitais, baseado não somente na televisão digital mas também na convergência tecnológica entre outras plataformas, também está sendo visto como algo que deve ser colocado em prática pelo governo.

Ao utilizar um processo de codificação de áudio e vídeo digital, a televisão digital também possibilita incluir dados no mesmo canal do fluxo de áudio e vídeo principal ${ }^{14}$. Esses dados podem ser utilizados em aplicações interativas, aperfeiçoando a experiência do telespectador.

A interatividade é vista como um dos destaques do Sistema Brasileiro de Televisão Digital Terrestre (SBTVD-T), e sua expressão se dá a partir de aplicativos voltados para a saúde, educação, serviços governamentais e outros serviços com oportunidades de informação e entretenimento. Entre os fatores dos quais depende o sucesso da interatividade está a consolidação do sinal digital em todo território nacional. Segundo dados da Anatel ${ }^{15}$, a tecnologia já está presente em mais de $46 \%$ dos lares da população brasileira, e a expectativa é que a cobertura de todo o país ocorra entre 2016 e 2020. Com a aproximação das datas de espetáculos esportivos em 2014 e 2016 no Brasil, a tendência é que, além da implementação e do aumento de aplicativos interativos disponíveis, ocorram testes de transmissão de tecnologias ainda mais inovadoras, como a terceira dimensão (3D) e a transmissão em 8K (Ultra High Definition).

Em síntese, parece-nos claro que o fundamento da revolução está bastante distante da trajetória de desenvolvimento e implantação da televisão digital. A televisão digital e seu potencial inclusivo, interativo e democrático não é revolução nos termos de subversão de um sistema político e social existente.

\section{ACIONAMENTOS TRANSGRESSORES}

Certas condições de entorno, no entanto, permitem que a aplicação da tecnologia exerça com maior ênfase seu potencial de renovação e inclusão. O emparelhamento 
e a articulação da tecnologia com os fundamentos da educação e da formação dos indivíduos gera outcomes propícios à subversão do modelo de inovação pautado somente no consumo. Os trabalhos de Prahalad ${ }^{16}$ alinham-se a essa perspectiva ao conceber determinados acionamentos do setor privado como meios de redução dos problemas crônicos da pobreza e desigualdade social, sem necessariamente solapar os pressupostos de obtenção de resultados, lucros e sobrevivência empresarial.

No âmbito do setor público, um exemplo de como um apropriado acionamento da tecnologia pode gerar impactos transgressores se revela no projeto Brasil 4D ${ }^{17}$, iniciativa da Empresa Brasil de Comunicação (EBC). A partir do modelo de interatividade definido nas normas do SBTVD-T, uma iniciativa piloto foi produzida de forma a levar capacitação profissional e serviços para populações em condições de pobreza no Brasil usando a televisão como ferramenta. Um grupo de cem famílias foi convidado a participar dos testes junto ao chamado Canal de Serviços do Governo Federal.

\section{CONSIDERAÇÕES FINAIS}

O processo de inovação é inescapável e necessário para os broadcasters. No entanto, o advento de várias possibilidades tecnológicas que visam à interação com a audiência e, portanto, uma mudança no modelo de negócio é vista ainda com muita reticência pelas emissoras. "Em um ritmo de inovação constante, fatores desconhecidos não são mais aceitáveis; o movimento deve ser controlado sob o risco de haver um colapso na coerência global"18.

Adorno, McLuhan e Lazarsfeld tiveram sua importância, mas atualmente pouco dão conta dessa nova ordem tecnológica ${ }^{19}$. Muito em breve, novas métricas de medição de audiência devem colocar em dúvida os atuais métodos de medição do audience trap que pautam as negociações de publicidade na TV tradicional.

Caminha-se, sem dúvida, em direção a um futuro conectado, móvel e convergente, em que as telas devem confluir um sem-número de conteúdos, sejam das emissoras, dos provedores de conteúdo, de amigos ou de qualquer pessoa que queira criar e compartilhar algo virtualmente. A expansão da internet sob a televisão parece ser um caminho sem volta e que pode agregar valores aos conteúdos tradicionalmente distribuídos pelas emissoras de TV aberta - se elas souberem se adaptar aos novos tempos.

\section{REFERÊNCIAS}

ABDALA, R.; CHIANCA, L.; CASTILLEJO, Á. G. Brasil 4D: Estudo de impacto socioeconômico sobre a TV Digital Pública Interativa. Disponível em: <www.ebc. com.br/sites/default/files/brasil_4d.pdf>. Acesso em: 21 out. 2013.

ALENCAR, M. S.; MADEIRO, F.; LOPES, W. T. A. History of Television in Brazil. IEEE Conference on History of Telecommunications 2010, Madri, Espanha, nov. 2010.
16. PRAHALAD, C. K. A riqueza na base da pirâmide. Porto Alegre: Bookman, 2006.

17. ABDALA, R.; CHIANCA, L.; CASTILLEJO, Á. G. Brasil 4D: Estudo de impacto socioeconômico sobre a TV Digital Pública Interativa. Disponível em: <www.ebc. com.br/sites/default/files/ brasil_4d.pdf $>$. Acesso em: 21 out. 2013.

18. STIEGLER, B. Technics and Time, 1. Stanford: Stanford University Press, 1998 , p. 42.

19. BARBOSA FILHO, A.; CASTRO, C., idem, p. 38. 
comunicação \& educação • Ano XIX • número 1 • jan/jun 2014

ANATEL. (2011). Cobertura da TV digital. Contagem da população. Disponível em: <www.anatel.gov.br/Portal/verificaDocumentos/documento.asp?numeroPub licacao $=276895 \&$ assuntoPublicacao $=$ Popula $\%$ E7 \% E3o \% 20alcan $\%$ E7ada\&caminh oRel=null\&filtro=1\&documentoPath=276895.pdf $>$. Acesso em: 08 mar. 2014.

BAUMAN, Z. Modernidade líquida. Rio de Janeiro: Jorge Zahar, 2001.

BARBOSA FILHO, A.; CASTRO, C. Comunicação digital: educação, tecnologia e novos comportamentos. 1. ed. São Paulo: Paulinas, 2008.

CASTRO, C. A produção de Conteúdos Digitais Interativos como Estratégia para o Desenvolvimento - um breve estudo sobre a experiência latino-americana em TV Digital. Trabalho de Pós-Doutorado. Cátedra Unesco em Comunicação, Universidade Metodista (Umesp), São Bernardo do Campo, 2011.

CASSIOLATO, J.E.; LASTRES, H. M. M. Sistemas de inovação e desenvolvimento: as implicações de política. São Paulo em Perspectiva, v. 19, n. 1, 2005.

CLARK, V.; PRIOLLI, G. O campeão de audiência. São Paulo: Best Seller, 1991.

ENCICLOPÉDIA INTERCOM DE COMUNICAÇÃO. José Marques de Melo (org.). São Paulo: SBEIC, 2010, v. 1, p. 1163.

GOFFIN, K.; RICK, M. Innovation Management: Strategy and Implementation using the Pentathlon Framework. 2. ed. Nova York: Palgrave Macmillan, 2010.

GÓMEZ, G. O. Comunicação Social e mudança tecnológica: um cenário de múltiplos desordenamentos. IN: MORAES, D. Sociedade midiatizada. Rio de Janeiro: Mauad, 2006.

CONSULTORIA J. LEIVA E FUNDAÇÃO GETÚLIO VARGAS. O que é cultura? Disponível em <www.jleiva.com.br>. Acesso em: 12 abr. 2011.

JENKINS, H. Convergence Culture. Nova York: New York University Press, 2006.

MARTIN, M. A linguagem cinematográfica. São Paulo: Brasiliense, 2003.

MATTOS, S. A. S. História da televisão brasileira. Uma visão econômica, social e política. 2. ed. Petrópolis: Vozes, 2002.

MATSUBARA, F. M.; KAWAMORI, M. Lightweight Interactive MultimediaEnvironment for TV. IEEE Transactions on Consumer Electronics, v. 57, n. 1, 2011.

PIAGET, J. Biologia e conhecimento. 2. ed. Vozes: Petrópolis, 1996.

PRAHALAD, C. K. A riqueza na base da pirâmide. Porto Alegre: Bookman, 2006.

PRENSKY, Marc. Digital natives, digital immigrants part 1. On the Horizon, v. 9, n. 5, 2001.

PROPP, V. Morfologia do conto maravilhoso. Rio de Janeiro: Forense Universitária, 1984.

STIEGLER, B. Technics and Time, 1. Stanford: Stanford University Press, 1998. 